\title{
The Global Ranking Regime and the Reconfiguration of Higher Education: Comparative Case Studies on Research Assessment Exercises in China, Hong Kong and Japan
}

Jun Li (junli1@hku.hk), Deputy Director and Associate Professor Education Policy Unit, Faculty of Education, University of Hong Kong

\section{Acknowledgements}

Empirical findings of this study are mainly from my research projects on "World-class Universities, Publication and Research Assessment: Rethinking the Mission of Higher Education in the Global Age" funded by the Research Development Fund of Worldwide Universities Networks (RDF/WUN Ref.: 4930217) and "China-Africa University Partnerships in Education and Training: Students, Trainees, Teachers and Researchers" funded by the Hong Kong Research Grants Council General Research Fund (RGC/GRF Ref.: CUHK842912). Special thanks go to the two funding agencies, the WUN research team (particularly Mayumi Ishikawa, Jiang Kai, David Post, Wenqin Shen and Xiaohong Tian), and anonymous participants and reviewers as well for its publication here. I bear sole responsibility for its contents, however. 


\title{
The Global Ranking Regime and the Reconfiguration of Higher Education: Comparative Case Studies on Research Assessment Exercises in China, Hong Kong and Japan
}

\begin{abstract}
The global drive for world-class universities is twinned with a radical movement to create research assessment indicators, and universities have never been pressured as much as today by global rankings. This paper aims to focus on how research assessment exercises have reconfigured the institutional missions of the university in terms of knowledge production, teaching and service address, by comparing three top research-intensive universities in Mainland China, Hong Kong and Japan. It critically investigates how far and in what ways academics in the three systems have been pressured to respond to these exercises. The empirical findings show that all the three cases have been affected severely and that Hong Kong universities are the most internationalized and Mainland universities are the most productive in research outputs, as also evidenced in recent QS rankings. The paper argues that the global ranking regime has created a Double Bind for East Asian universities, and has brutally dominated their institutional reconfigurations. To turn the tide, the manipulated emphasis, flawed methodology and unethical desirability of global university rankings and research assessment exercises should be avoided to help universities healthily and meaningfully focus on real missions to which they should commit themselves. Meanwhile, critical reflections and policy actions are particularly urgent on the indigenousness of knowledge exploration and production by higher education systems in East Asia and other post-colonial contexts. Furthermore, the paper anticipates that the importance of teaching and service will be revitalized in the new stage of East Asian universities, e.g., the Chinese University 3.0.
\end{abstract}

\section{Key words}

Ranking, research assessment, world-class university, Chinese University 3.0, academic life, China

It would be nice if all of the data which sociologists require could be enumerated because then we could run them through IBM machines and draw charts as the economists do. However, not everything that can be counted counts, and not everything that counts can be counted.

William Bruce Cameron (1963), p. 13.

The vast increase in bureaucracy...occasioned by the flourishing of a managerial ideology and the relentless demands of the state assessment exercise, means that academics have had little enough time to prepare their teaching even if it seemed worth doing....Points are awarded by the state inspectors for articles with a bristling thicket of footnotes, but few if any for a best- 
selling textbook aimed at students and general readers. Academics are most likely to boost their institution's status by taking temporary leave of it, taking time off from teaching to further their research.

Terry Eagleton (2015)

\section{Introduction}

The global drive for world-class universities is twinned with a recent movement to create research assessment indicators, and universities have never been dominated and pressured as much as today by the so-called global ranking regime, a series of assessment exercises in ranking and controlling outcomes for global status. Although the purposes and structures of university rankings and research assessment exercises have never been the same, quality has been the shared concern for both practices. In fact, national or institutional research assessment exercises have looked to global university rankings due to the wider publicity and aggressiveness of the latter. The twinned assessment schemes of higher education institutions (HEIs) have created the global ranking regime accelerated since the mid-2000s.

The global ranking regime and particularly university rankings used to take humble forms in their earlier stage, but have been aggressively spreading worldwide in recent decades. As a corollary, the landscape of higher education has been dramatically reconfigured to create "world-class" universities (Li, 2016): The ways of knowledge exploration and transfer have been narrowed to quantifiable metrics; publications defined by various research assessment exercises; scholarship and academic life as well have been fashioned to suit whatever can be measured as accountable; and ultimately, the mission of higher education has been reconfigured fundamentally and limited to a pragmatic orientation to serve this global ranking regime.

The impact of the global ranking regime has recently drawn much serious attention, worldwide, and there is a plethora of literature on it. However, how these rankings and research assessment 
exercises have reshaped universities' missions have remained under-explored with empirical data. Taking a case study approach, this paper aims to address the concern by comparing three top research-intensive universities, one each in Mainland China, Hong Kong and Japan, focusing on how research assessment exercises have reconfigured their missions in terms of knowledge production, teaching and service. In particular, it critically investigates how far and in what ways academics working at different institutional contexts have been pressured to respond to these exercises. A consideration of the empirical findings leads to several policy implications for the reform of higher education in future.

\section{The Paradoxical Phenomenon}

Quality assurance has been an increasing concern in the reform of higher education in recent decades (Harman, 2011; Teichler, 2011). As an alternative approach to quality monitoring and evaluation, global university rankings in general and research assessment exercises in particular have attracted wide attention from government policymakers, university leaders, academics, students and parents, as well as the general public (e.g., Chou, 2014; Shin et al, 2011; van Vught and Ziegele, 2012). Such global practices of quality monitoring and evaluation are viewed as serving "organizational effectiveness" (Shin, 2011) and "research quality and impact" (Harman, 2011) also as a "transparency tool" (van Vught and Westerheijden, 2012), an "audit culture" (Power, 2004) and an "accountability movement" (Toutkoushian and Webber, 2011). These endeavors can all be seen as elements in the global ranking regime, which results from a convergence from such forces as government-accountability, accreditation and commercial rankings, which are used to define excellence in higher education, valuable knowledge, and, at the grandest level, world-class universities (Gonzales and Núñez, 2014, 3). A key concern is raised as to how the global ranking regime has impacted the landscape of higher education in 
different settings (Hazelkorn, 2015), in the move from how to rank, to why to rank (Oguz, 2004), and indeed to so what to rank.

Related literature shows the co-existence of two contrasting scenarios. There are some situations where positive effects are observable to some researchers. For example, Shin (2011) argues that ranking and quality management contribute to "institutional quality and organizational effectiveness" (p. 19). In a similar vein, Harman (2011) makes the point that the global ranking practice pressures higher education institutions to renovate their traditional, inappropriate mechanisms of quality assurance and focus more on "bibliometrics" as well as other quantitative measurements of research assessment and impact (p. 49). Furthermore, van Vught and Westerheijden (2012) recognize it as a transparency tool which can have a positive impact on setting "bigger and higher standards" for research universities (p. 12). Given these opinions, university leaders are urged to participate in the global movement of competition for higher quality.

However, the negative impact on higher education tends to dominate the discussion of the phenomenon, as evident in the recent criticism by Terry Eagleton (2015), a prominent critic and public intellectual who takes a postmodern position. According to his observations, instead of government by academics a good deal of "Byzantine bureaucracy" exists in the British system, which is less privatized than its American counterpart: junior professors are little but dogs bodies, vice-chancellors behave as though they are CEOs, senior professors are now senior managers, and the air is thick with talk of "auditing and accountancy" on campus. It is likely that whole humanities departments will be closed down in the coming years in the midst of this debacle (Eagleton, 2015). Taking Taiwan as an example, Chou (2014) similarly observes that there are several negative effects on the reshaping of the institutional development of universities in Taiwan, which are summed up in the term SSCI Syndrome. 
Mayumi Ishikawa (2014) employs a multidimensional approach to analyze the threat of the global ranking regime to local scholarship through a study of research universities in the case of Japan, concluding that the exercises of ranking may fall short of addressing real needs of enhancing individual performance in pursuit of globally relevant research and ensuring equity among different generations of scholars; rather there is an increasing tendency for AngloAmerican academic circles to dominate the rest of the world. Gonzales and Núñez (2014) find from their review of relevant literature that the rankings regime may yield negative influences on the evaluation of faculty work, especially research, through the perpetuation of the following values or practices: (a) individualism; (b) standardization; (c) commodification and (d) homogenization (p. 8).

Although there has been some literature about the impact of the global ranking regime on changes in higher education, little attention has been paid, in either empirical or comparative approaches, to how research assessment exercises have reconfigured the landscape of higher education. This study aims to address this gap by collecting, analyzing and reflecting on firsthand data from three top research-intensive universities, one each in Mainland China, Hong Kong and Japan, focusing on how research assessment exercises have reconfigured their missions in terms of knowledge production, teaching and service. In particular, it investigates how far and in what ways academics working in different institutional environments have been pressured to cater to the demands coming from research assessment exercises.

\section{The Analytic Framework and Research Design}

As an institution that fosters a "basic determination to know" (Jasper, 1959, 20) the university has been traditionally expected to play three major roles in individual and societal development: the search for truth, the training of students, and the interpretation of knowledge and ideas, as 
noted by Abraham Flexner in his analysis of the modern American, English and German systems (Flexner, 1930, 6). Flexner's view was further carried forward by Clark Kerr (1963), the first Chancellor of the University of California at Berkeley in the 1950s, when he wrote about the uses of the multiversity. Quite recently, Jaroslav Pelikan (1992) explicitly defines the institutional functions of the university as research, teaching and duties to society, and Grant Harman (2006) classifies them into teaching, research and scholarship, and service (p. 309).

This study builds on this theoretical clarification of the core dynamics of the university and employs it as the analytic framework for data collection and analysis. More specifically, academic publications are used to indicate the research function of higher education, while teaching of undergraduate and postgraduate students and community services as two other key dimensions. Furthermore, the trilateral relationships among them are also of particular interest in this research, which aims to compare their interactions and impact in different socio-political, economic and cultural contexts under the global ranking regime.

This study is part of the project on "World-class Universities, Publication and Research Assessment: Rethinking the Mission of Higher Education in the Global Age" originally led by the author and sponsored by the Research Development Fund of Worldwide Universities Networks (RDF/WUN, Ref.: 4930217). Given the breadth of this study, a multi-site case study design was planned to generate similar and contrasting findings, with a purposive sampling strategy to identify three critical, research-intensive universities in each context of Mainland China, Hong Kong and Japan (please refer to the Preface of this special issue for more details of the general design of the project). Interviewees were identified with both male and female academics by snowball sampling strategies from two disciplinary areas, i.e., anthropology and education policy, as they are viewed as common for research in social sciences and educational sciences, respectively - both are sensitive to research outputs with a tradition long enough for comparisons over time. As this study looks into the impact of research assessment exercises in 
different times, more than a dozen participants were identified from two groups each in the two areas, junior and senior academics. Interviews were conducted for around 40 minutes each in the three case study institutions, respectively. Additionally, three data point years were used by this study to tabulate journal articles published by academics in the two areas of the three case study institutions in 1993, 2003 and 2013, respectively.

Data collection followed the ethical policies and principles by respective universities of the research team, and it was conducted from February 2014 to December 2015, with three types of data collected for this study: the tabulated quantitative data of journal articles published in the three data year points; qualitative data including interviews with and observations of junior and senior academics; and related documents and news reports about the three institutions. Consent was obtained with each interviewee and audio-recording were done for most interviews. Interview data were coded with three types of coding strategies, i.e., descriptive, interpretive and pattern (Miles and Huberman, 1994, 57).

\section{The Three Cases and Policy Contexts in China, Hong Kong and Japan}

Although the three cases in China, Hong Kong and Japan are all from Confucian heritage societies, which tend to put a high value on excellence in higher education (Li and Hayhoe, 2012), their policy contexts vary largely from each other.

Insert Table 1 here 


\section{The Top China University $(\mathrm{TCU})^{1}$}

TCU is one of the oldest and most prestigious higher education institutions in China. It is a leading public institution in the sense of institutional reforms that have built its world-class status upon its research outputs. TCU has been widely viewed as the first tier university in China that can compete with other world-class universities in the world.

TCU's reform has been profoundly influenced by China's three national agendas for building WCUs, i.e., Projects 211 and 985, and the National Evaluation of Baccalaureate Programs Project (NEBPP). Starting in 1993 and 1998, respectively, Projects 211 and 985 have aimed to improve the quality of teaching, research and administration of universities, and to make some of them world-class, and Project 985 has been particularly tailored to facilitate a great leap forward in building elite world-class universities with a limited number, with a huge public investment from both the central and local governments.

Almost at the same time China launched the NEBPP that aims to continuously monitor and improve the teaching and quality of universities. The NEBPP adheres to the principle of promoting reform and reconstruction of universities through assessment. Major measures used by the NEBPP include reviewing the institutional mission, faculty, teaching facilities and their utilization, program construction and teaching reform, teaching administration, teaching and learning style, and teaching effectiveness. Each of these seven indicators is "scientifically" designed and categorized into several sub-indicators. ${ }^{2}$ Since the NEBPP has been adopted nationwide and the results of its evaluation every five years are publicized as "Excellent", “Good”, "Qualified” or “Disqualified” by MOE’s Higher Education Evaluation Center, every

\footnotetext{
${ }^{1}$ Pseudonym, and hereafter.

${ }^{2}$ For more information about the NEBPP, please refer to the Higher Education Evaluation Center of the Ministry of Education: http://www.heec.edu.cn/en/index.jsp
} 
HEI in China views earning a good reputation through the NEBPP as a political accomplishment critical to their institutional success.

More recently, the China Discipline Ranking (CDR) by the China Academic Degrees and Graduate Education Development Center (CDGDC) under the MOE has taken substantial shape in assessing research performance of individual disciplinary areas of Chinese universities. Among the four core indicators is research outputs measured directly by journal articles, books and textbooks (CDGDC, 2016, April 22). Since the summer of 2016 the fourth round of such a nationwide assessment exercises has got into full swing. Normally the results of these assessments each time have been indirectly associated with government's budgeting available to individual HEIs in China.

\section{The Top Hong Kong University (THKU)}

THKU is one of the most prestigious higher education institutions in Hong Kong, and has often been ranked among the top 100 in the world by the QS World University Rankings. As a public institution, THKU is funded by the Hong Kong government with a British tradition of aegis under the University Grants Committee (UGC). From 1997 when Hong Kong returned to China as a special administrative region, the funding scheme has been adjusted to be more linked to the research performance of individual higher education institutions in Hong Kong.

Modelled on the British mechanism of quality assurance for HEIs, THKU has been regularly evaluated by the Research Assessment Exercise (RAE) since 1993. The RAE aims to assess the research quality of the eight UGC-funded institutions in Hong Kong in order to encourage world-class research, by using rigid measures of outputs, inputs and esteem as key indicators for making publicly accountable the allocation and re-allocation of institutional funding and recurrent grants, benchmarking outputs against international research standards. Research outputs are classified into five categories: world leading (4 star), internationally excellent (3 
star), international standing ( 2 star), regional standing (1 star), and unclassified, by employing the four definitions of scholarship from the Carnegie Foundation, i.e., discovery, integration, application and teaching (Boyer, 1990; Glassick et al, 1997).

The latest RAE carried out in 2014 introduced a new measure to the competition for public research funding among research universities: The results of annual competitions for the Research Grants Council (RGC) research grants are to gradually increase, over a course of nine years, accounting for half of the research allocation, and the RAE 2014 results informed the other half of the research allocation. Although the RAE is not intended to produce a league table of the UGC-funded institutions or be an assessment of individuals' research performance (The UGC, 2014, June), and results are communicated on a cost centre basis without disclosing the identity of individual academic staff, academics are widely pressured to meet the high expectation of individual cost centers and institutions as well.

\section{The Top Japan University (TJU)}

TJU is among the top national universities in Japan, with a history going back to the $19^{\text {th }}$ century when Japan was in the process of modernization through the Meiji Restoration. It was later merged as one of the seven Imperial Universities in Japan in the 1930s, and is widely recognized as among the top five comprehensive universities in the country.

Unlike China and Hong Kong, Japan has a higher education system dominated by a preponderance of private institutions. However, like in China and Hong Kong, public national universities in Japan have traditionally played a more significant role in research, closely monitored by the Ministry of Education, Culture, Sports, Science and Technology (MEXT). These national universities have been reorganized as corporations since 2004, intending to enhance their performance. Under the new system of National University Corporations, the MEXT lays out mid-term goals over a period of six years, which serve as the base for national 
universities to prepare their individual mid-term plans which must be approved by the MEXT. Based on these individual mid-term plans, the performance of national universities is evaluated at the end of the mid-term period by the former National Institution for Academic Degrees and University Evaluation (NIAD-UE), which was merged into the National Institution for Academic Degrees and Quality Enhancement of Higher Education (NIAD-QE) newly established on April 1, 2016. A key role the new NIAD-QE is to evaluate education and research activities based on requests from the Committee of National University Corporation Evaluation Committee (NUCC) under the MEXT.

The NUCE is an evaluation of national universities which measures their individual performances against their various developmental plans and mid-term goals for education, research and management. The Evaluation Guidelines and the Guidelines for the Performance Report are provided by the former NIAD-UE as the framework of such evaluations of national universities. Each national university is required to produce a performance report following these two guidelines. Their individual performances are then audited through the evaluation process based on document analysis and site visits, similar to China's NEBPP and CDR, which were introduced earlier. The objectives of the NUCE are twofold: (a) quality assurance and improvement of the education and research of national universities; and (b) their accountability as public institutions.

More importantly, MEXT has enforced a new system for allocating the fiscal budgets of national universities based on their evaluation results and institutional efforts, a similar mechanism that has been used by the UGC in Hong Kong. Along with the second round of medium-term evaluation and such new national initiatives as the "Global 30" and "Reinventing Japan" Projects, all aimed at fostering world-class universities, the huge pressure and fierce competition among institutions and research centers have converged in ways that affect 
individual faculty members, especially those who work at such research intensive universities as TJU.

\section{Research?}

To answer the research question on how research assessment exercises have impacted higher education systems in various policy settings, it is necessary to first understand how research has been configured in the institutional missions of universities. The findings of this study show that in all of the three cases research was highly valued and appreciated. And this is widely agreed by all participants in different disciplines and of different ranks in the TCU, THKU and TJU. Most interviewees endorsed the view that research is one of the core missions of universities, especially of research-intensive universities. Almost all interviewees agreed that they were highly motivated to serve this mission in their respective institutions.

To give an example from the TCU case, Prof. $\mathrm{Wang}^{3}$ recently retired as the former Director of the Institute of Higher Education from the university, but still serves as a professor emeritus of TCU. As a senior faculty member he felt research had been a priority for TCU in his experience. He made the following supportive comments: "The university should follow its original nature....and it is in the university that research and truth can be explored." Comparing teaching and service with research, he insisted that research should be placed as the first priority among the three for his university, which is research-intensive. Similarly, as senior faculty members, both Prof. Lau in the field of education at THKU and Prof. Takamura in the field of anthropology at TJU confirmed that their universities also highlighted the importance of research, seeing such a priority as necessary for the mission of their respective institutions in

\footnotetext{
${ }^{3}$ Pseudonym, and hereafter.
} 
the new global era. Such views were echoed by almost all participants in the three case study institutions.

Although participants in the three case study institutions all observed the importance of research in their respective universities, the policy settings were different among China, Japan and Hong Kong. For example, interviewees at TCU viewed research not only as one of their institutional missions, but as an imperative for socio-economic development in a domestic context and for national competitiveness in the ongoing process of globalization, often measured by global ranking schemes. The similar institutional rationale was observed in the Japanese context, as evidenced in TJU, but with a stronger sense of improving and maintaining their status in order to be more competitive globally in many areas, as also found by Ishikawa (2009). The cases from China and Japan manifest a strong catch-up or even competition mentality at both national and institutional levels. Additionally, TJU has emphasized the importance of research as at least equal, if not higher, than those of teaching and service.

The Hong Kong case suggested that research endeavors were more for the enhancement of its global status as an individual institution, as well as serving the economic competitiveness of Hong Kong as a special administrative region, as evidenced by Postiglione and Jung (2013). Specifically, as a public institution THKU aimed at enhancing the world-class status of research to help transform Hong Kong into an international hub of higher education in the AsiaPacific Region and beyond, according to the participants interviewed at THKU.

When the three core missions of the university are compared, research is increasingly highlighted as the first priority at THKU before teaching and service, according to Prof. Lau. He added that teaching is important to a research-intensive university, but research comes ahead of it definitely. Institutionally THKU divides the three dimensions evenly in its annual appraisal exercise for all academics, but in practices research is usually viewed as the first 
criterion to evaluate the overall performance of everyone, as observed by Prof. Lau. He further proved that junior professors tended to be more strongly committed to research than teaching and service.

\section{Research for Assessment?}

The importance of research has been systematically configured into the institutional missions of the three case study universities, especially manifest in the form of regular, institutional assessment of the research outputs of faculty members, which creates various pressures on academics on campus. Fundamental differences emerge when the institutional impact of these research assessment exercises is examined across the three cases.

As shown by the quantitative findings (Table 2 and Figure 1), the three case study institutions shared the same historical trends of publications in the field of educational policy and anthropology from 1993 to 2013. It is observed that THKU tended to be most severely affected by the RAE from 1993 to 2013, and its journal articles per faculty member increased sharply from 0.47 to 1.50 , with the fastest growth rate at $220 \%$ among the three universities over the same period. This finding suggests that THKU has been mostly involved in research assessment exercises and is the system which has been pressured the most among the three cases in terms of the growth rate of journal articles per faculty member over time. The reason for this phenomenon may be related to its RAE mechanism that has associated research outputs of individual institutions with UGC's annual budgeting, which makes growth rates of journal articles per faculty member the most sensitive among the three universities.

During the same period, TCU shared the same pattern by the NEBPP with TJU by the NUCE, and their publication rates increased remarkably at almost same pace of $50 \%$, respectively from 
1.38 to 2.08 and from 1.50 to 2.25 , suggesting that both TCU and TJU remained less and similarly affected by the global ranking regime, compared with THKU. Meanwhile, TCU appears slightly more productive in terms of the overall publication rate (2.30) than its Japanese counterpart (2.19) over the past two decades. In other words, it can be observed that TCU is the most productive system in journal articles per faculty member among the three cases.

In general, publication rates per faculty member jumped from 1.00 in 1993 to 1.84 in 2013 across the three institutions, with an overall growth rate at $84 \%$, nearly doubled within the 20 years. This finding evidences that research productivity represented by journal article publication rates per faculty member have increased remarkably in East Asian researchintensive universities within the past two decades.

Insert Table 2 here

Insert Figure 1 here

Such quantitative findings can also be observed from the qualitative data. In terms of research pressure, it is apparent that senior faculty members tended to cater more for their personal interest and motivations of knowledge exploration, rather than being pressured to do research. As a renowned senior in the field, Prof. Wang at TCU mentioned that he had been long committed to and continuously involved in research activities throughout his whole professional life, and he was still active in leading several research projects even after he had retired. Another senior professor in the field of anthropology, Mr. Chao in his early 50s, 
confirmed that his research outputs had been all produced based on his personal academic interest over a long time, not pressured by the institutional assessment of TCU:

In the earlier times there were no such things as annual appraisal for promotion or research assessment for tenure at my university. That time not everyone published, except for a few very senior colleagues who just published something. What we measured were the academic interest in and commitment to research, instead of research outputs, not mentioning the indicator of quantity. Now, as a senior professor I have no fear to be measured by the current tough assessment - If my university measures me as incompetent - highly impossible - I can easily move around to work at other institutions.

Prof. Chao was extremely confident in his reputation for research excellence, and explained that he can enjoy the freedom of job relocation if TCU required him to comply with its institutional criteria of research appraisal. Similar experiences were evident in Hong Kong and Japan, as confirmed respectively by Prof. Lau at THKU and Prof. Takamura at TJU who were both senior and very active in all kinds of research activities. Junior faculty members seemed to carry forward this tradition of research interest and motivation, consciously or unconsciously, and this can be observed across all the three cases.

It was true that these junior faculty members working at research-intensive universities were already prepared for higher expectation and tougher appraisals from their institutions. But still not all junior faculty members shared the same optimism and high morale. Assistant Professor Zhang at TCU in the field of education, was in his fourth year and felt direct pressure relating to his research outputs as measured by the research assessment exercises of TCU. He mentioned he must work as hard as possible to make himself more prepared and competitive when the time came for his tenure application one year later. 
Another example can be found from top Japanese universities. Miss Yamaguchi, a new assistant professor in anthropology, feared the institutional pressure of research assessment exercises at TCU and has been devoting herself to research activities all the time. Due to the busy schedule of her research, she was even unable to find time for her personal life, still being single in her late 30 s. She was unable to smile during the interview, summarizing her academic life in the following way:

I have to be focused on research so that I can publish more papers in the coming years, or I will otherwise risk losing my position from my university.... The job competitiveness is fierce and my university has a high expectation for everybody. If I lag behind I will surely lose my job... Therefore, I have led my personal life simply like this: coming to my office every day from my rented apartment at 6:30am in the early morning and going home from my office in the late evening - sometimes very late until mid-night. I was lucky that my commute time is not that long every trip-it's just less than one hour.

Yamaguchi's stress was echoed by her peer at TJU, Prof. Saka in the field of education. Before the interview was started with him, he showed several academic books and papers in Japanese or English, which obviously indicated his pride in his greatest achievements over the past two decades. He explicitly indicated that research assessment exercises were very important to ensure the institutional status of his university, and he had been fully committed to supporting the competitive mechanism of TJU.

\section{Research for Assessment of SSCI Journal Articles in English?}

The pressure particularly on some junior professors can be further understood by looking into the changing impact of research assessment exercises in recent decades, which reflects how 
research-intensive universities have responded to the ongoing global competition in research excellence as measured by various global ranking schemes. The investigation of this dimension shall help answer the last question on the impact of research assessment exercises: how has it changed over time?

As shown by the quantitative findings (Table 3 and Figure 2), the overall publication ratios between English and Chinese languages jumped from 0.17 in 1993 to 0.51 in 2013 across the three institutions, with an overall growth rate $198 \%$, almost tripled within the 20 years. This is a clear signal that publication preferences in East Asian research-intensive universities have moved rapidly to so-called international journals dominated by English language.

Individually, THKU tended to be again most severely affected by the RAE from 1993 to 2013, and its publication ratios between English and Chinese languages almost doubled from 1.25 to 4.25 over the two decades, with the highest overall publication ratio (1.45) and the rapidest growth rate at $240 \%$ between English and local languages in the past 20 years. This finding suggests that THKU has been most actively involved in the internationalization process of higher education among the three cases in terms of research outputs, due to the colonial history and post-colonial context of Hong Kong universities with a capitalist tradition, which is the most sensitive to the global ranking phenomenon.

TJU shared the same pattern by the NUCE with TCU by the NEBPP, and their publication ratios between English and native languages only increased slightly or even remained flat, respectively, suggesting that both TJU and TCU were less affected by the internationalization process of higher education, compared with THKU, while TCU appeared the least sensitive to the NEBPP and TJU marginally more sensitive to the NUCE. By and large THKU has been the most internationalized and in a leading status among the three top research universities, as 
measured by the two indicators of overall publication ratio and growth rate between English and Chinese languages over time.

Insert Table 3 here

Insert Figure 2 here

The qualitative data support the quantitative findings, and show that the historical trend can be explained by the changing nature of research assessment exercises, e.g., more demanding in terms of both quality and the use of English instead of native languages.

In the case of TCU, research assessment exercises directly use publications in SCI, EI or SSCI journals as a core indicator for faculty advancement, substantiation and awards. Specifically, publications are systematically measured by (a) the number of publications and/or (b) the number of SCI, EI or SSCI journal articles. These criteria vary across different disciplinary areas and among different ranks of professorship. For example, to get a full professorship in natural sciences: (a) 10 and (b) 7, or (a) 8 and (b) 5 plus a high-quality monograph; and to get an associate professorship in natural sciences: (a) 6 and (b) 3, or (a) 4 and (b) 2 plus a monograph. Weighted bonuses are given for indexed journal articles in English. Such measurements were termed as "evaluationism" by academics at TCU.

Additionally, the global status of TCU in different ranking systems are used explicitly as for institutional promotion in faculty or student recruitment. For example, Essential Science Indicators, QS Ranking are used as advertising strategies for student recruitment. Furthermore, 
national rankings in (1) university ranking; (2) faculty quality; (3) graduate quality and (4) media impact are also highlighted in commercial campaigns for student recruitment.

The emphasis on SCI, EI and SSCI journal articles in English for evaluation was supported by both juniors and seniors who tended to view the global ranking regime as one way of the internationalization and standardization of research outputs, but seniors were not really affected whereas juniors were. In terms of topic and language preference for publications, both seniors and juniors tended to emphasize local relevance over time, while they were also open and tolerant, as both tended to value more their impact at the local level instead of the international. This is an interesting finding in that TCU calls for global impact of its research but its faculty did not fully agree, as expressed in the following way by Assistant Professor Zhang:

In general my colleagues don't have many publications in English, and there is no significant change. One of the reasons [for this] is that publications in English have fewer readers from our domestic academia, therefore have little impact. For the majority of my colleagues here publications in English are not the first choice. However, there are two to three colleagues who are active in English publications, which is good for the global impact of higher education research from China.

THKU is better aligned with established research assessment exercises, which do not explicitly use the indicator of SCI, EI and SSCI journals for faculty advancement, substantiation and awards. But THKU does have such expectations for English publications, which were hidden in the external and internal review processes. As these two processes are crucial to faculty substantiation, normally no academics dare to ignore these hidden rules. In this sense THKU is even more aggressive than TCU.

Based on interviews at THKU, senior members tended to agree on the enhancement of the global standards set by various assessment schemes whereas juniors were compliant. The same 
was observed as seniors were not really affected while juniors were. Additionally, both seniors and juniors tended to emphasize the local relevance of publications over time. As academics in Hong Kong have the tradition of publications in English, both senior and junior academics valued their impact at local as well as international levels, with juniors exhibiting a greater preference for publication in SCI, EI or SSCI journals. One junior professor felt the institutional pressure of research assessment exercises in this way:

As academics in Hong Kong enjoy the best salary rates in the world, universities here must make accountable their performance in research and education to the Hong Kong government and the general public, which has exerted huge pressures on us.... There is a weird, performance-counts-all mentality like a ghost haunting Hong Kong universities, that is, if I am unable to meet the high expectation in terms of research outputs my university can easily find somebody else who can replace me, and this is the case in other local institutions too. I don't feel I myself am that treasured by my university.

Compared with THKU and TCU, TJU seems to be affected less aggressively by the global movement of research assessment, but still follows the "audit culture" mandated by the NUCE under the MEXT. To meet the mid-term objectives that were audited every six years by the NIAD-UE (revamped as the NIAD-QE since April 1, 2016), TJU encourages its faculty to publish their research outputs in refereed journals as one of the bibliometric indicators for career advancement and job substantiation. Institutionally SCI, EI or SSCI journal articles are not explicitly used in its research assessment exercises, but there are unwritten criteria giving preference to such publications used by individual faculties or departments for appointment and promotion. Sometimes these preferences become explicit for junior academics, e.g., internationally refereed or even SCI journal articles are required for Ph.D. students in the field of science or engineering. 
Similar to their counterparts in China and Hong Kong, Japanese interviewees at TJU all viewed the addition of global standards of research assessment exercises as conducive and necessary to improving the academic status of TJU. Prof. Takamura agreed that this practice helped make Japanese universities more "visible" in the international community, but she also had concerns over how the new global parameters should be "properly used". Prof. Yamaguchi shared her worries on how she may be capable of producing "decent publications" in international refereed journals to meet such measures for her promotion in the years to come:

Although I am new in the academic world, I am clear it's not an easy game for me to survive and grow, especially as a woman. It will be nice to have some decent publications in SSCI journals, but it's very difficult. You know English is not my native language, and writing in English is a painful process.... Having publications in English, however, will surely make me more competitive and safer in my job prospects at TJU, so I have to make every hard effort as I can to overcome it. I am of course not the only colleague here who worries about this.

\section{Implications}

In the new global age higher education is undergoing remarkable reconfigurations in responding to many new challenges, and the global ranking regime is just one of its kind. Traditionally the three core missions of the university have been facilitated and shaped as well by institutional financing, governance, faculty and students, socio-cultural environment, etc. Within just one decade the global ranking regime has overtaken these traditional factors, and become a pervasive, phenomenal and powerful force that systematically controls higher education almost everywhere in the globe. This is particularly true when publication becomes 
a major indicator of research productivity by research assessment exercises which have increased pressures on institutions and individual scholars (Post, 2012).

As evidenced in this study, research has been a core mission for all the three case study institutions, and all academics endorsed such a mission as fundamentally important, institutionally and personally. Although research is just one of the three core missions of the university, it has been increasingly made more important than ever before, thus is widely seen as the first priority if compared with two other core missions, i.e., teaching and service. The danger here, however, is that all research assessment exercises and ranking schemes have taken - boldly and relentlessly - the single form of quantifiable indicators to measure "The noncommensurability of valuable things", though "not everything that can be counted counts, and not everything that counts can be counted" (Cameron, 1963). Thus "publish or perish" has become a reality of academic life, and unfortunately, has in large part contributed to academic corruption and dishonesty on campus in many higher education systems.

Findings from the three cases manifest that research is reconfigured in the regular mechanisms of evaluation used for faculty advancement, job substantiation and awards. These mechanisms have created the so-called "evaluationism" in China, "performance-counts-all mentality" in Hong Kong, "audit culture" in Japan, or "SSCI Syndrome" in Taiwan, with a specific emphasis on publications in refereed journals. When publications are evaluated, their international impact becomes an imperative metric either encouraged or mandated by a given national or societal context and by individual institutions. In most cases publications in English are more recognized as English is a global "imperial tongue" (Altbach, 2013) which dominates SCI, EI or SSCI journals, traditionally controlled by Western publishing or indexing agencies.

Such a global ranking regime has callously created a dilemma or a Double Bind for East Asian universities, which are struggling very hard for a balance of various institutional missions to 
respond to global competition and local demands at the same time. The struggle has made academic life on campus much tougher than ever before, as experienced by the junior Japanese woman scholar. Worse than that, academics must make difficult decisions on where to publish their research findings - a dilemma of publishing globally and perishing locally or publishing locally and perishing globally, as argued by Hanafi (2011) in universities in the Arab East. To turn the tide, the manipulated emphasis, flawed methodology and unethical desirability of global university rankings and research assessment exercises should be avoided to help universities healthily and meaningfully focus on real missions to which they should commit themselves. Meanwhile, critical reflections and policy actions are particularly urgent on the indigenousness of knowledge exploration and production by higher education systems in East Asia and other post-colonial contexts.

Needless to say, this study is limited to the three top research-intensive universities in the East Asian Region, where institutional diversity and dynamism abounds. Have other types of university been affected similarly by the global ranking regime? If yes, how have these universities been reconfigured, either in common with others or individually? How may these reconfigurations have changed institutional missions of the university, e.g., teaching quality? And how have academic life and student life been affected? These are all urgent questions that deserve further research in the future.

\section{Conclusion}

Thanks to globalization paved by colonialism and post-colonialism, the global landscape of higher education has been dominated, more or less, by the modeling of Western traditions represented by Anglo-American systems, a model of the university captured by Guy Neave (2001) and Jun Li (2012). A ubiquitous manifestation of such a Western dominance is the 
hegemony of English language as the lingua franca around the world over the past century, as evidenced empirically by this study in research-intensive universities in Mainland China, Hong Kong and Japan. The global ranking regime, typified by university ranking schemes and research assessment exercises, has turned out to be just another enhanced form of such a modelling carried forward in the new global age, but with a wrong post-colonial mentality. The dilemma created by such a global paradoxical phenomenon has generated multitudinous imperatives and tremendous pressures as well for an institutional reconfiguration of East Asian universities, as observed by many other researchers (e.g., Ishikawa, 2009; Marginson, 2010; Postiglione and Jung, 2013; Yonezawa, 2013, etc.).

East Asian universities have their unique institutional traditions (Hayhoe, 1995; Li, 2016). For example, the Taixue (The Imperial University) established and institutionalized in China since $124 \mathrm{BCE}$ was the first higher education institution in the world, one thousand years earlier than Western models. Since the late 1990s universities in China have striven for a new stage of development, i.e., the Chinese University 3.0, rejuvenating from its cultural heritage with as self-mastery and intellectual freedom, humanist (zhi-xing) mission and institutional diversity (he'er butong) (Li, 2012; 2016). It will be interesting to observe how this emerging East Asian model can balance the global, regional and local missions of the university (Cheung, 2012).

While some East Asian universities may take the new global challenges of ranking as opportunities to improve their institutional quality and status, many have experienced a weakened commitment to teaching and service that should be seen equally important and fundamental as research. It is anticipated, probably within the next few decades, that the importance of teaching and service will be revitalized in the new stage of East Asian universities 


\section{References}

Altbach, P. G. (2013). The international imperative in higher education. Boston: Sense Publishers.

Boyer, E. L. (1990). Scholarship reconsidered: Priorities of the professoriate. New York: The Carnegie Foundation for the Advancement for Teaching.

Cameron, W. B. (1963). Informal sociology, a casual introduction to sociological thinking. New York: Random House.

CDGDC. (2016, April 22). The Fourth National Discipline Assessment formally Launched. $\begin{array}{lllll}\text { Retrieved on } & \text { May } & 25, & 2016 & \text { from }\end{array}$ http://www.cdgdc.edu.cn/xwyyjsjyxx/zlpj/pgpsdtxx/281819.shtml

Cheung, A. B. L. (2012). How Hong Kong Universities balance the global and the regional. In B. Adamson, J. Nixon \& F. Su (Eds.), The reorientation of higher education: Challenging the East-West dichotomy (pp. 95-112). Hong Kong: CERC/Springer.

Chou, C. P. (2014). The SSCI Syndrome in higher education. Rotterdam, the Netherland: Sense Publishers.

Eagleton, T. (2015, April 6). The slow death of the university. The Chronicles of Higher Education. Retrieved April 10, 2015 from http://chronicle.com/article/The-Slow-Deathof-the/228991

Flexner, A. (1930). Universities: American, English, German. Oxford: Oxford University Press.

Glassick, C. E., Huber, M. T., \& Maeroff, G. I. (1997). Scholarship assessed: Evaluation of the professoriate. San Francisco, CA: Jossey-Bass \& The Carnegie Foundation for the Advancement for Teaching.

Gonzales, L. D., \& Núñez, A.-M. (2014). The ranking regime and the production of knowledge: Implications for academia. Education Policy Analysis Archives, 22 (31), 1-20.

Hanafi, S. (2011). University systems in the Arab East: Publish globally and perish locally vs publish locally and perish globally. Current Sociology, 59 (3), 291-309.

Harman, G. (2011). Competitors of rankings: New directions in quality assurance and accountability. In J. C. Shin, R. K. Toutkoushian \& U. Teichler (Eds.), University rankings: Theoretical basis, methodology and impacts on global higher education (pp. 35-53). Dordrecht: Springer.

Harman, G. (2006). Research and scholarship. In J. J. F. Forest \& P. G. Altbach (Eds.), International handbook of higher education (pp. 309-328). Dordrecht: Springer Science+Businesses Media B. V. 
Hayhoe, R. (1995). An Asian Multiversity: Comparative reflections on the transition to mass higher education in East Asia. Comparative Education Review, 39 (3), 299-321.

Hazelkorn, E. (2015). Rankings and the reshaping of higher education: The battle for worldclass excellence ( $2^{\text {nd }}$ ed.). New York, NY: Palgrave Macmillan.

Ishikawa, M. (2014). Ranking Regime and the Future of Vernacular Scholarship. Education Policy Analysis Archives, 22 (30), 1-22.

Ishikawa, M. (2009). University rankings, global models and emerging hegemony: Critical Analysis from Japan. Journal of Studies in International Education, 13 (2), 159-173.

Jasper, K. (1959). The ideal of the university (Trans. H. A. T. Reiche \& H. F. Vanderschmidt). London: Lowe \& Brydone.

Kerr, K. (1963). The uses of the university. Cambridge, MA: Harvard University Press.

Li, J. (2016). Chinese University 3.0 in a global age: History, modernity and future. In P. C. I. Chou \& J. Spangler (Eds.), Chinese education models in a global age: Transforming practice into theory (pp. 15-35). Singapore: Springer.

Li, J. (2012). World-class higher education and the emerging Chinese model of the university. Prospects: Quarterly Review of Comparative Education, 42 (3), 319-339.

Li, J., \& Hayhoe, R. (2012). Confucianism and higher education. In J. A. Banks (Ed.), SAGE encyclopedia of diversity in education (Vol. 1, pp. 443-446). Thousand Oaks, CA: Sage.

Marginson, S. (2010). GLOBAL: Research: A force for globalisation. Retrieved on January 3, 2016 from http://www.universityworldnews.com/article.php?story=20100326113121559

Miles, M. B., \& Huberman, A. M. (1994). Qualitative data analysis: An expanded sourcebook ( $2^{\text {nd }}$ ed.). Thousand Oaks, CA: Sage.

Neave, G. (2001). The European dimension in Higher Education: An excursion into the modern use of historical analogues. In In J. Huisman, P. Maassen \& G. Neave (eds.), Higher education and the nation state: The international dimension of higher education (pp. 1372). Oxford: Pergamon.

Oguz, A. (2004). Ranking competition: How much to endeavor to move up? Unpublished M.A. thesis, Emory University.

Pelikan, J. (1992). The idea of the university: A reexamination. New Haven, CT: Yale University Press.

Post, D. (2012). Rank scholarship. Comparative Education Review, 56 (1), 1-17.

Postiglione, G. A., \& J. Jung. (2013). Frameworks for creating research universities: The Hong Kong case. In J. C. Shin \& B. M. Kehm (Eds.), Institutionalization of world-class university in global competition (pp. 237-254). Dordrecht: Springer. 
Power, M. (2004) 'The risk management of everything', The Journal of Risk Finance 5(3): 5865.

Shin, J. C. (2011). Organizational effectiveness and university rankings. In J. C. Shin, R. K. Toutkoushian \& U. Teichler (Eds.), University rankings: Theoretical basis, methodology and impacts on global higher education (pp. 19-34). Dordrecht: Springer.

Shin, J. C., Toutkoushian, R. K., \& Teichler, U. (2011). University rankings: Theoretical basis, methodology and impacts on global higher education. Dordrecht: Springer.

Teichler, U. (2011). Social contexts and systemic consequence of university rankings: A metaanalysis of the ranking literature. In J. C. Shin, R. K. Toutkoushian \& U. Teichler (Eds.), University rankings: Theoretical basis, methodology and impacts on global higher education (pp. 54-69). Dordrecht: Springer.

The UGC. (2014, June). Research Assessment Exercise 2014. Retrieved January 3, 2016 from http://www.ugc.edu.hk/eng/doc/ugc/rae/gn_201406.pdf

Toutkoushian, R. K., \& Webber, K. (2011). Measuring the research performance of postsecondary institutions. In J.C. Shin, R. Toutkoushian \& U. Teichler (Eds.), University rankings: Theoretical basis, methodology and impacts on global higher education (pp. 123-144). Dordrecht: Springer.

van Vught, F. A., \& Westerheijden, D. F. (2012). Transparency, quality and accountability. In F. A. van Vught \& F. Ziegele (Eds.), Multidimensional ranking: The design and development of U-Multirank (pp. 11-23). Dordrecht: Springer.

van Vught, F. A., \& Ziegele, F. (2012). Multidimensional ranking: The design and development of U-Multirank. Dordrecht: Springer.

Yonezawa, A. (2013). Rankings and information on Japanese universities. In P.T.M. Marope, P.J. Wells \& E. Hazelkorn (Eds.), Rankings and accountability in higher education: Uses and misuses (pp. 171-186). Paris: UNESCO. 
Table 1 Statistical Profiles of the Three Cases (2015)

\begin{tabular}{lccc}
\hline & TCU & THKU & TJU \\
\hline Undergraduate Students & 15,000 & 16,000 & 16,000 \\
\hline Master's Degree Students & 19,000 & 1,600 & 4,600 \\
\hline Doctoral Students & 10,000 & 2,000 & 3,200 \\
\hline International Students & 3,300 & 3,500 & 2,100 \\
\hline Schools & 62 & 9 & 16 \\
\hline Faculty & 4,500 & 3,000 & 4,900 \\
\hline
\end{tabular}

Note. Data collected from the official website of the three cases, respectively. 
Table 2 Statistical Trends of Journal Articles and Faculty Members (1993-2013)

\begin{tabular}{lcccr}
\hline & $\mathbf{1 9 9 3}$ & $\mathbf{2 0 0 3}$ & $\mathbf{2 0 1 3}$ & Total \\
\hline TCU & $18 / 13$ & $66 / 21$ & $54 / 26$ & $138 / 60$ \\
\hline THKU & $9 / 19$ & $55 / 23$ & $42 / 28$ & $106 / 70$ \\
\hline TJU & $15 / 10$ & $26 / 9$ & $18 / 8$ & $59 / 27$ \\
\hline Overall & $42 / 42$ & $147 / 53$ & $114 / 62$ & $303 / 157$ \\
\hline
\end{tabular}

Fig. 1 Statistical Trends of Journal Articles per Faculty Member (1993-2013)

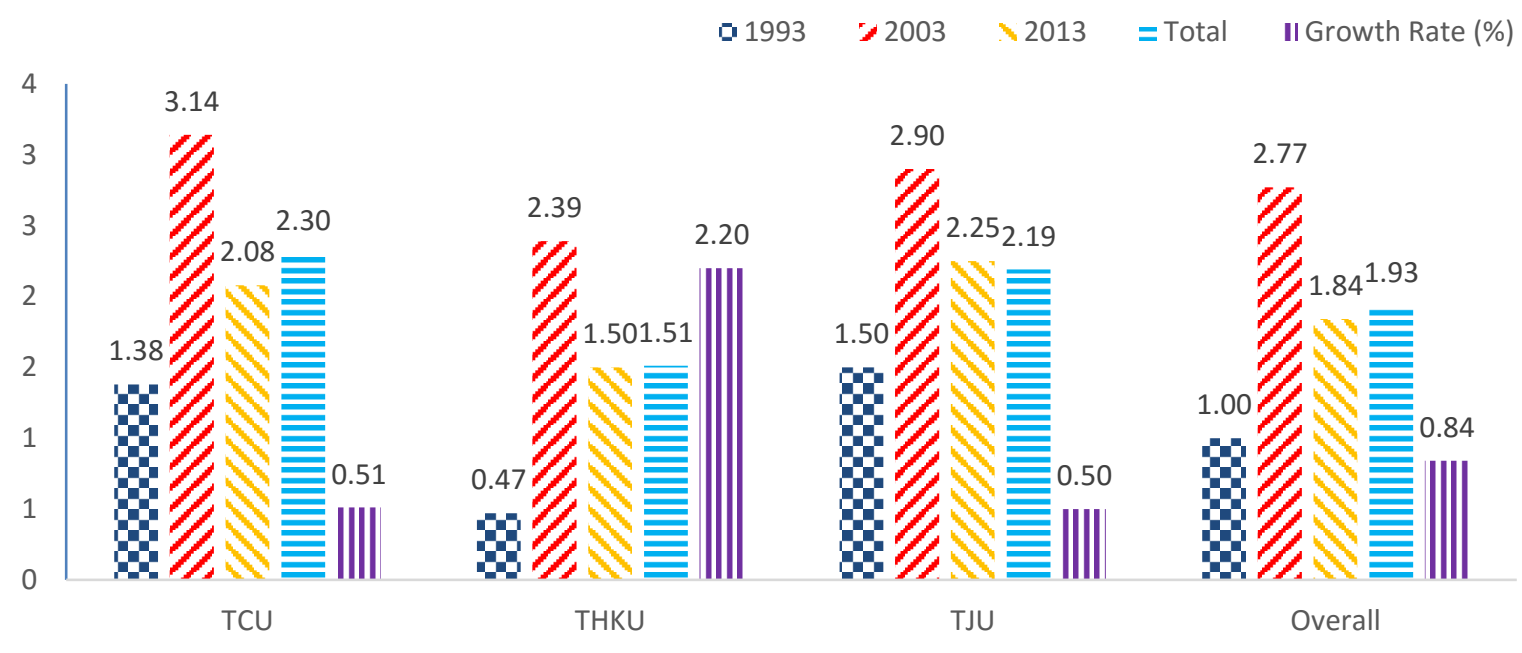


Table 3 Statistical Trends of Journal Articles in English and Native Languages (19932013)

\begin{tabular}{lcccr}
\hline & $\mathbf{1 9 9 3}$ & $\mathbf{2 0 0 3}$ & $\mathbf{2 0 1 3}$ & Total \\
\hline TCU & $1 / 16$ & $4 / 60$ & $3 / 50$ & $8 / 126$ \\
\hline THKU & $5 / 4$ & $26 / 31$ & $34 / 8$ & $64 / 43$ \\
\hline TJU & $0 / 15$ & $1 / 25$ & $1 / 17$ & $2 / 57$ \\
\hline Overall & $6 / 35$ & $31 / 116$ & $38 / 75$ & $74 / 226$ \\
\hline
\end{tabular}

Note. Data excluding those that were published in bilingual journals or other local languages.

Fig. 2 Ratio Trends of Journal Articles in English and Native Languages (1993-2013)

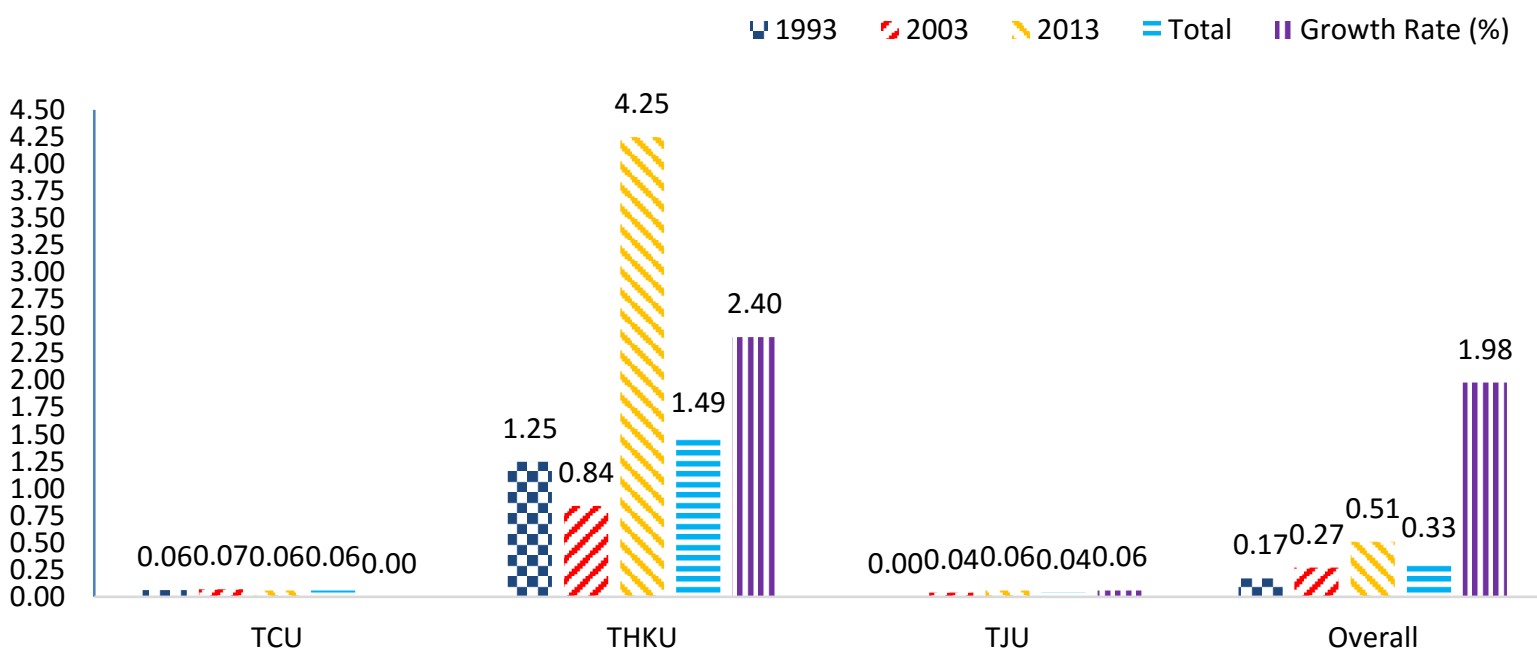

Note. Data excluding those that were published in bilingual journals or other local languages. 